thonght to be a simple uniform protoplasmic substance. The discoveries regarding many cells suggest that all organic tissues of definite function possess also a structure of complex and definite character, which may determine, in ways of which we have as yet no perception, the direction and character of the minute motion between their atoms, and of the effect of that which reaches them. Moreover, it must be remembered that if this seems complex almost beyond credibility, it is not likely that any conception of the nature of these processes can be offered which does not present the like repellent aspect. We are accustomed to talk of the action of nerve centres, of their "inhibition," of "lines of resistance," of "increased resistance" and "lessened resistance," of the effects of over-action and the like. In speaking thus of these processes we seem to be describing their nature. In reality, as I have said, we are doing scarcely more than repeating in terms of a different character a description of the phenomena we observe. We fancy that we are explaining when we are merely translating words. I do not know that any attempt has yet been made to pass beneath the surface and to frame any theory of the actual processes on which the observed phenomena depend. But I feel sure that, whatever be the nature of any hypothesis that can be framed, it must be at least as complex as that which I have suggested, at least as unfamiliar, and must seem as strange. The processes that underlie such phenomena we can trace, or seem to trace, in dim outline as processes of energy in the domain of life; but this malady, as a disease, brings us to the point where that which we can trace is limited by that of which we can only see the influence. It confronts us with the influence of life itself, of which the nature is beyond our comprehension; conspicuous enough it is, but quite impenetrable to our discernment. The essential feature of the malady as a disease-that is, as a recurring process-is the fact of its recurrence. This involves the renewal of capacity for action which we have already noted in observing the features of muscular activity, but it brings before us, also, the fact that there is not only renewal of capacity, but increase of tendency. It is this which makes epilepsy a disease; it is by this that action causes overgrowth. However minute may be the excess of that which replaces over that which passes away, the excess is certain, both of matter and the motion it bears. Not only does the renewal so perfectly correspond to the loss as to make long-continued repetition of the action possible, but it must in some way involve an increased disposition for the like release of motion under the same stimulus, so that the process is more readily produced. This is the secret of all education and training, and of the physical basis of memory. It is the secret also of functional disturbance as a self-perpetuating disease. Epilepsy is a disease because the tendency to what we call "discharge" is increased each time the tendency has its effect. This renewal of material and of energy, and this increase, in both are the result of the vital power of nutrition. The marvellous ability of the living structure to appropriate to itself, from the organic compounds which come into relation with it, those that ezactly correspond to the elements which it has lost, to appropriate them, moreover, in increased amount, is the effect of that vital influence which first builds up the structures, which maintains them, and renews them until a term approaches-when it fails. In youth so strong, in age so feeble, this power of renewal in each alike has disease in its capacity. Perverted energy in early life is thus angmented, defective nutrition in later life is increased in its imperfection. We must not, however, follow further this line of thought. The thread of vital influence might be traced through many an intricacy; but we should thereby be no more able than before to unravel the warp and woof of the strange web, or even to discern distinctly the pattern they have woven on it.

And so, gentlemen, in mystery we begin - and end. Was it not Coleridge who said : "In wonder all knowledge begins, in wonder it ends, and admiration fills up the interspace"? Not altogether true nor everywhere, and yet who is there that does not feel that an earnest effort to perceive that which is unseen leaves him on a higher level, and if at his old standpoint he has a better view. Whether the effort I have made to-night can be thus described or not, I feel that it leaves us more conscious of the mystery that includes so much, and seems essentially impenetrable - the mystery that holds the secret of our being. Search as we may, with eyes however earnest and however aided, that which we call "life" eludes our search and resists our efforts. We may, indeed, trace the relations of matter and of the energy it bears-their entrance into the domain of life, their exit, their effects. We see them dimly shadowed now and then within the luminous mist, but the mist obscures our sight, and the light it radiates bides by its own brightness. We must be content with what knowledge we can gain, secare or insecure, and, while using it as best we may, should realise, in all humility, how much there is we cannot know, and yet we cannot doubt.

\section{ON STATE INSPECTION OF CREAMERY DAIRIES.}

BY J. J. WELPLY, M.D. Q.U.I., MEDICAT OFFICER OF HEALTH, BANDON.

IN THE LANCET of April 21st, 1894, I drew attention to the dissemination of infectious diseases by our creameries and made some suggestions as to the means by which this might be avoided. Further personal observations, as well as information supplied by others, have convinced me of the reality of the danger I then pointed out, and have conclusively proved the uselessness of any protecting measures which fall short of those then recommended-viz., firstly, thorough and frequent dairy inspection by competent and independent inspectors or "sanitary policemen"; and, secondly, compulsory notification of all cases of illness occurring in dairies which send milk to creameries. I cannot add any thing essential or new to what was contained in the article referred to, but a few cases may be worth recording, as they afford practical proofs of the necessity for, and value of, the regulations previously suggested.

CASE 1. - Mr. A- received milk from a creamery the supply of which became implicated through a dairy where typhoid fever had broken out. At no time was the separated milk drunk by any of the occupants of the house, yet Mrs. A- and the man who drove the milk car to and from the creamery contracted typhoid fever. Other sources of infection were absolutely excluded, and it was evident that the separated milk was the means by which the disease was brought to the household. Pigs and cattle were fed with the separated milk, and the persons who handled it took food subsequently without thorough cleansing of the hands. Some of the vessels used in pouring out the milk were also employed in otber ways.

Such cases prove that there is danger to the occupants of a farm from the contaminated milk-supply of a creamery, even though the separated milk be not used as an article of human diet. When an albuminous liquid such as milk at blood heat receives a quantity of typhoid bacilli, and is then carted, perhaps for hours, under a hot sun, these microbes must increase enormously, for all the conditions-temperature, proteid medium, absence of sunlight, \&c.- encourage their multiplication, so that each farmer eventually receives gallons of a fluid teeming with disease germs that cannot fail to be a source of danger to everyone who handles either it or the vessels in which it is kept. It is also evident that by boiling merely the portion of milk intended for human consumption all possibility of infection is not removed; nothing short of the boiling of the whole quantity of the separated milk and the scalding of all vessels in which it was contained can effectually remove the danger.

CASE 2.- - Typhoid fever broke out in the household of Mr. B in December, 1893. Shortly afterwards I attended at a house about one mile distant, where milk from $\mathbf{M r}$ B-_._'s farm had been received. There were seven persons living in this house, and as they knew of the presence of fever in the dairy some of them refused to use the milk, but others took it. All the former, four in number, escabed, while the three who drank the milk contracted typhoid fever. On the appearance of the disease in Mr. B- 's dairy his establishment became short-handed, and the milk was then actually sent to a neighbouring creamery, as this entailed less trouble.

The necessity of compulsory notification of every illness occurring in dairies which supply the public or send their milk to creameries is strongly shown by this case. Such a law is not universal at present, and Mr. B- was able to supply the public and send his milk to a creamery, although the danger of infection thereby was proved by the cases in the neighbouring house where the milk was used. Mr. Stafford, Local Government Board medical inspector, in a 
series of most useful recommendations made by him to the Tralee sanitary board in connexion with the fever epidemic in Castleisland, complained that medical practitioners granted certificates of freedom from infection to dairy people in whose houses infectious diseases had quite recently been prevalent. He thought that " some interval, whether a week or ten days or a fortnight, should elapse between the removal of the patient and the supplying of milk to the creamery.' To ask for such an interval is not an arbitrary proceeding, and the demand is based on many valid reasons. Not only does it give an opportunity for more effectually destroying all contagion by repeated disinfections, fumigations, and cleansings, but, further, it allows time for the development of fresh cases which may have been in the incubation stage at the time of the removal of the first patient. The latent stage of typhoid fever is liable to considerable variation, but medical antborities give it as most commonly about a fortnight, and though it probably is often extended to a much longer period I think a certificate of freedom from infection may be granted fourteen days after the removal of the patient, provided that the other members of the household be then free from suspicious symptoms. During this fortnight most thorough disinfection of the dairy, vessels, houses, and even bedding, which may have been soiled, should be performed.

CASE 3.-The milk-supply of a creamery situated in Sanitary District No. 1 having become contaminated, typhoid fever was conveyed by it to the family of Mr. Clived in Sanitary District No. 2. A servant in Mr. C-'s employment also sickened and went to her father's house in a third sanitary district, at a distance of about ten miles, and five of ber family contracted the disease. Subsequently another of Mr. C_-'s servants fell ill and was treated on his master's farm, but still Mr. C-_'s milk-supply to the creamery was not stopped.

Here is seen the great difficulty a medical man often meets with when he is seeking the starting-point of an infectious outbreak. The practitioner who treated Mr. C-s servant after her removal to Sanitary District No. 3 had no suspicion that her illness was directly contracted from the creamery in Sanitary District No. 1, six miles from Mr. C_-'s residence, seeing that she came direct from Sanitary District No. 2, ten miles from the house where this medical man first gaw her. Different rural districts are now brought into relation in a manner hitherto unknown, and as their medical officers of health may have no communication with each other it is evident that badly conducted dairies do a much larger amount of mischief through creameries than practitioners or the public are aware of. I know of nothing that would have been more calculated to protect the milk-supply of the creamery referred to than the Infectious Disease (Notification) Act ; by it the possibility of spreading infection would have been reduced to a minimum.

The public in many places are partly protected by legislation which regulates the sale of milk direct to the customers. These regulations are embodied in the Contagious Diseases (Animals) Act and in others, but none of them have been universally adopted, nor is it probable that they will he for a considerable time, as the various local sanitary authorities have the option of putting them in force or not. F or many years the press, lay as well as medical, has rendered valuable service in educating the public by pointing out the dangers of impure milk. yet the non-adoption of these Acts in many places is to be accounted for by the perilons unconcern with which infection is still viewed in rural parts. The complete absence of inspection that is enjoyed by many vendors of milk at present cannot be generally known. In a recent article Professor J. P. Sheldon says : "Every farmer who wishes to sell milk to the public is required to take out a licence which is based on a certificate from the sanitary inspector, who has satisfied himself that the premises are clean, and that the water-supply is pure and ample. There can be no doubt that this is a wholesome regulation." No thoughtful person can dissent from the latter comment, yet it is to be regretted that in numerous places the sale of milk goes on without any such restrictions, and everywhere the creamery supply appears to be left uninfluenced, though the public require as much protection from impure milk when it goes to the factory as when it is intended for the retailer. One reason for the latter statement I have already referred to ${ }^{1}$ - viz., that the milk coming from an infected farm is sent back as separated milk to as many dairies as deal with the creamery, and each of these is thus rendered liable to an outbreak of disease, and, as a dairy distributing milk, to become in its turn a most active centre of infection. All these infected dairies continue to supply the creamery, and the produce of the latter thus becomes contaminated from an increased number of infected sources. Again, a few dairymen send only a portion of their milk to the factory, the remainder being retailed direct to their own customers - an arrangement which spreads the epidemic among households having no direct communication with a creamery. Case 2 is an example of this mode of propagation, and others have come under my notice. It has been urged by Professor Long that the sale of separated milk should be entirely prohibited, as one form of milk adulteration would be thereby suppressed. He has had experience which justifies him in stating that some unscruprlous dealers mix it with whole milk, thus making a double profit. Though starting from a different standpoint, my experience led me to a similar conclusion. Mr. D- was in the habit of buying separated milk ostensibly for the purpose of feeding pigs. Milk from his own cows he retailed, and the contamination of the creamery milk was followed by fever among Mr. D__'s customers. Whether there was intentional adulteration or only accidental tainting in this case, it affords an additional reason for protecting the public by adequate inspection of creamery dairies.

While the old system of butter-making was in use I did not see an epidemic of typhoid fever among the farming class. When that disease then appeared in a dairy-not retailing milk-it sometimes spread more or less throngh the inmates, but never in my practice to neighbouring farms. This fact is explained by the complete independence of the water-supply on most of the farms in my district, the formation of the land effectually protecting the wells from pollution by sewage from adjoining farms. However, the first case of typhoid fever seen by me after the local introduction of creameries was followed by an epidemic widely spread among the surrounding dairies. It is believed by many that the Contagions Diseases (Animals) Act, the Infectious Disease (Notification) Act, and the Infectious Disease (Prevention) Act are quite sufficient to meet the dangers called into existence by the creamery sfstem. The general adoption of all these Acts would undoubtedly be a much needed and most useful advance on our present unprotectec state, but, as already mentioned, there is no likelihocd of more than their partial adoption, nor do I believe that, unassisted by further enactments, they would be able to effectually cope with the requirements of this modern development of dairy farming. The Infectious Disease (Notification) Act only affects the district that adopts it; consequently farmers who live in adjoining district $s,{ }^{2}$ where the Act is not in force, need not notify the presence of disease occurring in their families even while they send milk into the former districtan objection which is fatal to the efficient working of this Act, as many dairymen supply creameries that are in sanitary districts far removed from the farms which yield the milk. Where the Infectious Disease (Prevention) Act is in force, if "the medical officer of health is in possession of evidence that any person in the district is sulfering from infections disease attributable to milk supplied within the district from. any dairy situated within or without the district," he can, if authorised by an order from a justice, inspect such dairy and get the animals therein inspected by a qualified veterinary surgeon. He shall then report to the local authority, who "may thereupon give notice to the dairyman to appear before then within such time-not less than twenty-four hoursas raay be specified in the notice." After his appearance. the local authority "may make an order to stop the sale of this milk witlin the district." The slowness of the legal machinery certainly gives ample opportunity for the spread of disease previously to the stopping of the sale of the contaminated milk, and where the Act is not already in force six weeks at least must pass from the date of special notice before the section mentioned sball exterd to the district. Furthermore, there is no provision made for simultaneously preventing the sale of the infected milk in neighbouring districts, which may still be sent to creameries situated elsewhere. Instead of these cumbrous proceedings ready and direct means are required for checking infection the

2 If an epidemic breaks out in a district in which this Act is not in force, and the local authority then desire to adopt it, six weeks at leas must elapse between the date of notice conrening the necessary meet in of the sanitary authority and the date on which the Act shall come into
operation. 
moment it is discovered or even suspected. Section 34 of the Contagious Diseases (Animals) Act provides for the registration and inspection of dairies. cowsheds, and milkshops, and is a necessary and usefal Order; but its adoption inot obligatory, and consequently it has been only a partial snccess. I know of more than one local sanitary authority that refused to appoint an inspector under this section, though they were asked to do so by the Local Government Board immediately after their respective districts had been widely visited by typhoid fever, the result of infected weparated milk. ${ }^{3}$

In July, 1894, the Limerick bench of magistrates bela that the Food and Drugs Act did not apply to milk sold to creameries, and they therefore dismissed a summons against a man for such adulteration. In a recent outbreak of fever in the Carrick-on-Suir union Dr. Moran reported that on the appearance of the disease on a certain farm the cows were transferred to an adjoining one, where the milking was carried on by the inmates of the infected house, and the milk after this exposure to infection was sold to the same creamery that the farmer had been previously prohibited from supplying. These are not examples of mere failure of administration of our present laws, but they are proofs of the necessity of fresh legislation required by a system the dangers accompanying which were not fully known when our recent Acts were framed. To render our existing laws at ail efficient they should be extended to every part of the Uaited Kingdom, and not confined to those districts whose sanitary authorities are sufficiently enlightened to adopt them; but, in order to grapple with the matter thoroughly, rules such as are enforced by the continental creameries should be made compulsory, and should be carried out under State supervision. I know that all necessary regulations are rigidly followed in many of our dairies and creameries, but in others they are completely ignored, and they will continue to be so until the State compels their adoption. Disease can also be conveyed by the cream, and an outbreak of scarlet fever at South Fensington was thus accounted for. Professor Lane Notter traced several cases of typhoid fever to the use of cream procured at a dairy where this disease had broken out, and Dr. Thorne Thorne saw cases of typhoid fever and of diphtheria that were caused by cream from infected milk. He explained the implication of the cream as "merely the mechanical effect of the oil globules in rising taking with them the germs to the surface." 2erhaps equal danger does not exist with cream obtained by the separator, as the tendency would be to have the heavier bacteria driven forcibly from the centre where the lighter cream collects.

The discoveries of Professor Bang of Denmark, and of Mr. Beebe of the New York Health Department, threaten to considerably widen the interest of the whole qaestion, and to make the demand for reform imperative. It was formerly thought that cheese and butter could not convey disease germs, but Professor Bang exploded this gratifying belief when he proved that both these products of the dairy are capable of deriving living and active tubercle bacilli from the milk. Since then there has been an uneasy suspicion that other disease germs may also find a suitable home in the same articles of diet, but in the absence of positive proof these fears seldom found expression. Now, however, Mr. Beebe has demonstrated that over $30001 \mathrm{~b}$. of cheese contained the Klebs-Löfler bacillas, and on investigation it was found that a fatal case of diphtheria had occarred in the family that supplied milk to the factory in which the cheese was made. Many creameries make an inferior cheese from separated milk, but the more important question is, Can this germ, or the bacillus of typhoid fever, find its way from the milk into the butter? At present there is no proof that such can occur, but, reasoning from analogy, the conclusions canno be reassuring. It is now known that the diphtheria bacillus can so pass in cheese-making; the heat used in this manufacture is not capable of destroying the germ, and one cannot point to any process in the making of butter that is calculated to do so, as the acid developed in the ripening of cream is not fatal to the typhcid bacillus. Butter contains about 16 per cent. of water, which is derived from the milk, and it must have been by means of this that the tubercle bacilli discovered in butter by Professor Bang were conveyed, and undoubtedly there is some danger, no matter how small, of

3 In the late outbreat in Castleisland, which was " elearly traced to infected milk," there were between 800 and 900 cases of typhoid fever yet on its

otber pathogenic germs passing over in a similar way, though, for the reasons mentioned just now, it is probable that, other things being equal, the presence of disease germs in butter is less to be feared when the cream from which it was made has been separated by the centrifugal machine; the weakness of our modern method of butter-making does not lie in the process of manufacture, but in the mixing together of the products of all sorts of dairies which are frequently under no supervision whatever.

In conclusion, it is undeniable that many diseases bave been conveyed by milk which was either procured from infected animals or was subsequently contaminated by the addition of impure water \&c.; that both cheese and butter have derived the tubercle bacillus from milk; that cheese has in the same way become impregnated with the diphtheria bacillus; and that several pathogenic germs, once they get into butter, can live there for considerable periods, cholera bacilli having been found in it thirty-two days after they were purposely introduced, typhoid bacilli after three weeks, and tubercle bacilli nearly three months later. To follow batter obtained from a suspicious source and to conclusively prove that harm results from its use is a task surrounded with almost insuperable difficulties, and mere negative results in such an important question cannot be considered as final. It is not in a spirit hostile to an important industry that I direct attention to these matters, but to impress on the State the necessity of adopting measures similar to those which are in force in the most flourishing agricultural countries of the Continent. In Germany a dairyman who sends adulterated milk to a creamery renders himself liable to a fine of $3 s$. for every quart of milk delivered. In Denmark, if milk be sent from a house in which infectious disease exists, a fine of $f 5$ is inflicted on the delinquent; creamery dairies are regularly seen by an inspector; and "veterinary surgeons visit the farms once a fortnight, when every case of disease among the cattle is isolated." Our own agriculturists would be benefited by the universal adoption of such rules, but the public health has even higher and more urgent claims. In the words of Professor Crookshank, "the health of the community roust take a first place; the happiness and prosperity of our country and the preservation of our imperial supremacy largely depend apon keeping our invisible foes in check and maintaining the highest possible standard of public health." But in spite of all our boasted advance in sanitary science these foes still come in what should only give us life and strength, for "there is death in the pot," and it has been my endeavour to expose one unguarded channel by which it gains entrance.

Pustscript. The cases in the houses of Mr. B - and Mr. C- did not come under the notice of the medical officers of health for their respective districts, and, the Infectious Disease (Notification) Act not being in force, no official information was supplied by occupiers or medical attendants. Bandon, Ireland.

\section{THYROID ADENOMA AND CYSTIC ACCES-} SORY THYROID; REMOVAL.

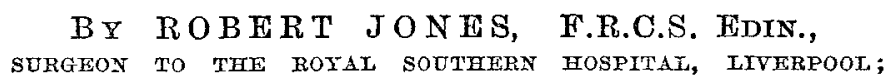
AND

W. THELWALL THOMAS, F.R.C.S. ENG., ASSTSTAKTT SURGEON TO THE ROYAL INFIRMARY, LIVERPOOL.

THE growth occurred in a patient aged twenty-seven years. When quite a little girl her parents noticed a small, freely movable lump under the skin of the left side of the neck, just above the collar-bone. The swelling was painless and "grew with her." In her twentieth year she consulted Mr. Whitehead of Manchester, who examined the neck and told her it consisted of enlarged glands and not to worry about it; he recommended the local application of tincture of iodine. The only inconvenience the growth caused, according to her statement, was an occasional feeling of choking when she lay down in bed. She is a married woman and has one child. Four and a half years ago another enlargement appeared higher up in the neck on the same side, near Adam's app'e, but the original swelling appears to have remained quiescent about this period, only to increase recently, which cansed her to consult 